OPEN ACCESS

Edited by:

Federico lovino,

Karolinska Institutet (KI), Sweden

Reviewed by:

Fabricia Petronilho,

Universidade do Sul de Santa

Catarina, Brazi

Jaqueline Generoso,

Universidade do Extremo Sul

Catarinense, Brazil

*Correspondence:

Rodrigo Hasbun

Rodrigo.Hasbun@uth.tmc.edu

Specialty section:

This article was submitted to

Bacteria and Host,

a section of the journal

Frontiers in Cellular and

Infection Microbiology

Received: 06 August 2020

Accepted: 23 October 2020

Published: 23 November 2020

Citation:

Gundamraj S and Hasbun R (2020)

The Use of Adjunctive Steroids in

Central Nervous Infections.

Front. Cell. Infect. Microbiol. 10:592017.

doi: 10.3389/fcimb.2020.592017

\section{The Use of Adjunctive Steroids in Central Nervous Infections}

\author{
Shalini Gundamraj ${ }^{1}$ and Rodrigo Hasbun ${ }^{2 *}$ \\ ${ }^{1}$ Cornell University, Ithaca, NY, United States, 2 Department of Internal Medicine, UT Health McGovern Medical School, \\ Houston, TX, United States
}

Central nervous system (CNS) infections continue to be associated with significant neurological morbidity and mortality despite various existing therapies. Adjunctive steroid therapy has been employed clinically to reduce inflammation in the treatment of CNS infections across various causative pathogens. Steroid therapy can potentially improve clinical outcomes including reducing mortality rates, provide no significant benefit, or cause worsened outcomes, based on the causative agent of infection. The data on benefits or harms of adjunctive steroid therapy is not consistent in outcome or density through CNS infections, and varies based on the disease diagnosis and pathogen. We summarize the existing literature on the effects of adjunctive steroid therapy on outcome for a number of CNS infections, including bacterial meningitis, herpes simplex virus, West Nile virus, tuberculosis meningitis, cryptococcal meningitis, Angiostrongylus cantonensis, neurocysticercosis, autoimmune encephalitis, toxoplasmosis, and bacterial brain abscess. We describe that while steroid therapy is beneficial and supported in pathogens such as pneumococcal meningitis and tuberculosis, for other diseases, like Listeria monocytogenes and Cryptococcus neoformans they are associated with worse outcomes. We highlight areas of consistent and proven findings and those which need more evidence for supported beneficial clinical use of adjunctive steroid therapy.

Keywords: meningitis, encephalitis, steroids, central nervous system infections, brain abscess, cysticercosis

\section{INTRODUCTION}

Central nervous system (CNS) infections involve the brain, spine, and associated membranes, and are linked to significant neurological morbidity and mortality, with long term consequences in survivors that affect the quality of life and activity of daily living (ADLS) (Erdem et al., 2017; Sulaiman et al., 2017). CNS infection broadly can be categorized as encephalitis, meningitis, or intracranial suppurative complications (e.g., brain abscess), with a broad range of causal organisms and clinical presentations. CNS infections can either originate by hematogenous spread (e.g., bacteremia, viremia), by retrograde neuronal invasion (e.g., viral infection through axonal transport such as rabies, Naegleria fowleri) or by contiguous spread of microorganisms (e.g., post cranial trauma or surgery, implementation of medical hardware into the brain or spine, or by parameningeal spread from a focus such as sinusitis or mastoiditis) (Archibald and Quisling, 2013; Koyuncu et al., 2013). Various bacteria, fungi, viruses, and parasites can be the source of CNS infection, which often presents nonspecifically with headache, fever, altered mental status, and 
behavioral changes (Dorsett and Liang, 2016). Precision in diagnosis, however, is essential to treatment, which varies across CNS infection. Despite the use of antimicrobial therapies neurological morbidity and mortality remains high for certain pathogens such as Streptococcus pneumoniae (Steel et al., 2013). Of all the adjunctive therapies that have been evaluated to date only adjunctive steroids have shown benefit in some CNS infections. Adjunctive steroids can ameliorate the host's inflammatory response to the infection that account for the neurological morbidity associated with the CNS infection. In contrast, in some CNS infections, the use of steroids has no clear beneficial effects or is detrimental with worse outcomes (Fitch and van de Beek, 2008). In this review, we will review the available data for the use of adjunctive steroids in the most common CNS infections and make clear recommendations for its use or not.

\section{PATHOPHYSIOLOGY FOR USE OF ADJUNCTIVE STEROIDS IN MENINGITIS}

Meningitis is characterized by inflammation of the subarachnoid space (space between two membranes (i.e., meninges) that surrounds the brain and spinal cord). Meningitis can be caused by bacteria, viruses, fungus, amebic, parasites, mycobacteria or due to noninfectious causes. Patients typically have abnormalities in the cerebrospinal fluid (CSF) such as elevated white blood cells (WBC), elevated protein (due to alterations in the blood brain barrier), and low glucose in some cases. The presentation of meningitis can be classified as acute (symptoms for less than 5 days), subacute (symptoms 6-30 days), or chronic (symptoms for more than 30 days) (Sulaiman et al., 2017). Presentation clinically varies according to the age of the patient, the causative agents, and the presence of underlying conditions (Hasbun et al., 2018). Once bacteria invades the meninges and disrupts the blood-brain barrier, it rapidly replicates in the subarachnoid space (van de Beek et al., 2016a). In the physiological response to infection, blood vessels become leaky allowing fluid, leukocytes, and other larger particles involved in fighting infection to enter the meninges and the brain (Dando et al., 2014). This process causes severe inflammation, which has been shown to increase the adverse outcomes of the infection. Steroid therapy has been employed to reduce the inflammatory response commonly exhibited in meningitis, although its effects vary by the study population studied and by the pathogen (Hoffman and Weber, 2009). Corticosteroid therapy can reduce inflammation by suppressing multiple activated inflammatory genes (encoding pro-inflammatory cytokines. and chemokines, inflammation mediators, adhesion molecules, inflammatory enzymes, etc.) through primarily reversing histone acetylation, by decreasing cell activation and recruitment and stabilizing lysosomes, by temporarily alleviating the leaky blood brain barrier, and by interacting with DNA recognition sites to activate the transcription of anti-inflammatory genes in higher concentrations in humans (Coyle, 1999; Barnes, 2006).
In animal models of bacterial meningitis, studies have shown outcomes to worsen based on the degree of inflammation (Scheld et al., 1980; Tauber et al., 1985; Brouwer et al., 2018). This inflammatory response can be reduced in the CSF by the administration of corticosteroid therapy, resulting in improved outcomes for meningitis in animal models (Scheld et al., 1980; Tauber et al., 1985). Thus, the use of corticosteroids has been investigated and employed in meningitis as adjuvant therapy over the past 30 years but must be further investigated in some infections.

\section{BACTERIAL MENINGITIS BY PATHOGEN}

Bacterial meningitis is a severe infection and inflammation of the meninges, the membrane surrounding the brain and spine, due to bacterial invasion into the subarachnoid space (Hoffman and Weber, 2009). The condition is associated with high mortality and neurological morbidity rates, with the most common causal pathogens including S. pneumoniae (i.e., pneumococcal), Neisseria meningitides (i.e., meningococcal), Haemophilus influenzae, and Listeria monocytogenes (Hoffman and Weber, 2009). Due to the development and implementation of vaccines against $H$. influenzae type b, S. pneumoniae, and N. meningitidis the incidence of bacterial meningitis has been reduced to 1-2/ 100,000 in children (Hasbun et al., 2018). In infants from 4-6 weeks, the dominating etiologies are Streptococcus agalactiae, Escherichia coli, other Enterobacteriaceae, and L. monocytogenes. In children older than 6 weeks up to adults of age 50 years, $S$. pneumoniae, $N$. meningitidis, and $H$. influenzae are the dominating etiologies of infection. In both adults over the age of 50 years and immunocompromised individuals of all ages, S. pneumoniae, N. meningitidis, $H$. influenzae, and L. monocytogenes prevail (Hasbun et al., 2018).

\section{S. pneumoniae}

$S$ pneumoniae is the leading cause of bacterial meningitis in the USA (Castelblanco et al., 2014). A review in 2018 of corticosteroid treatment effects in 25 trials across 2,511 children and 1,517 adults showed there was no significant change in mortality found overall with steroid therapy, although an effective mortality reduction was seen for $S$. pneumoniae meningitis from $36 \%$ to $29.9 \%$. The reduction in mortality for $S$, pneumoniae meningitis in 16 high-income countries was attributed to the use of adjunctive steroid therapy as compared to patients who did not receive steroid therapy. Patient outcome was not significantly different with the use of adjunctive steroids in low-income countries, which made up 9 of the 25 analyzed studies. Dexamethasone was the specific corticosteroid administered as adjunctive therapy in 22 of the trials, while hydrocortisone and prednisone were administered in the remaining 3 studies (Brouwer et al., 2018). No significant adverse effects were reported in the clinical studies by the use of adjunctive steroid therapy. The lack of effect of corticosteroid use in low-income countries, contrasted with significant reductions in mortality with corticosteroid adjunctive treatment for 
S. pneumoniae in high-income countries, is most likely due to the delay in patient presentation and treatment in low-income countries after inflammation in the CNS has already begun and progressed (van de Beek et al., 2016b). A 2002 randomized control trial on the effects of dexamethasone treatment in adults with meningitis similarly found a reduction in mortality and adverse outcomes, seizure incidence, and cardiorespiratory failure in contrast with the placebo group in pneumococcal meningitis (de Gans and van de Beek, 2002) (see Table 1). Dexamethasone corticosteroid adjunctive therapy has been shown to reduce mortality in pneumococcal meningitis and is a recommended therapy by the Infectious Diseases Society of America (IDSA), European and United Kingdom guidelines (Tunkel et al., 2004; NICE UK, 2010; McGill et al., 2016; van de Beek et al., 2016b). The implementation of dexamethasone treatment in the Netherlands has shown a decrease of $10 \%$ in the mortality rate of pneumococcal meningitis (Brouwer et al.,
2010). A study of 26,429 adults from 2011-2014 with a discharge diagnosis of meningitis or encephalitis showed that only patients with pneumococcal meningitis had a significantly reduced mortality with the use of adjunctive intravenous steroids. The study had 572 patients with pneumococcal meningitis and showed a decrease in hospital mortality rate with the use of steroids [(6.67\% with and $12.5 \%$ without steroids, $(\mathrm{P}=0.0245)$ ] (Hasbun et al., 2017) (see Table 1). Recently, delayed cerebral injury (DCI) in patients with bacterial meningitis has been described in up to $4 \%$ of patients and has a possible association with the administration of adjunctive steroid (Gallegos et al., 2018). Pathological studies suggest a cerebral vasculitis, thromboembolism of large arteries, and infectious intracranial aneurysms (Engelen-Lee et al., 2018). Components of the pneumococcal cell wall can be seen weeks after the initial presentation and may be a source of resurging inflammation after the initial immunosuppression by

TABLE 1 | Studies and Significant Findings on Adjunctive Steroid Therapy for Bacterial Meningitis Treatment by Pathogen.

\begin{tabular}{lll}
\hline Reference & Pathogen N $\quad$ Primary Findings
\end{tabular}

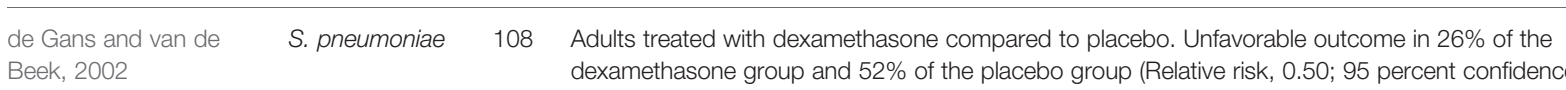
dexamethasone group and $52 \%$ of the placebo group (Relative risk, $0.50 ; 95$ percent
interval, 0.30 to 0.83; $P=0.006$ ). Dexamethasone associated with a reduction in risk of unfavorable outcomes (relative risk, 0.59; 95 percent confidence interval, 0.37 to $0.94 ; P=0.03$ ) and reduction in mortality (relative risk of death, 0.48 ; 95 percent confidence interval, 0.24 to 0.96)

Brouwer et al., $2010 \quad$ S. pneumoniae 709 Cohort of dexamethasone treatment in 84\% of episodes (2006-2009) compared to cohort of dexamethasone treatment in 3\% (1998-2002). Rates of death (20\% vs. $30 \% ; p=0.001)$ and hearing loss (12\% vs. 22\%; $p=0.001)$ were lower in 2006-2009 cohort.

Castelblanco et al., 2014 S. pneumoniae 21,858 Incidence and inpatient Mortality decreased between 2005 (0.049 per 100000 people) and 2008 (0.024 per 100000 people) compared with between 2002 (0.073 per 100000 people) and 2004 (0.063 per 100000 people; RR 0.5720, 95\% Cl 0.4303-0.7582). Temporal association of improved outcomes with recommendations of corticosteroids in clinical practice since 2004

Glimåker et al., $2016 \quad$ S. pneumoniae 115 Adults treated with corticosteroids compared to those not given corticosteroids showed lower mortality (10.2\% vs. $21.3 \%, p<0.001)$. Recovery without sequelae observed increased in corticosteroid-treated compared with non-corticosteroid-treated patients (45.2\% vs. $35.1 \%$, $\mathrm{p}<0.05)$

Hasbun et al., 2017

S. pneumoniae

Brouwer et al., 2018

Gallegos et al., 2018

S. pneumoniae

S. pneumoniae

Mclntyre et al., $1997 \quad$ H. influenzae

Brouwer et al., $2018 \quad$ H. influenzae

Heckenberg et al., $2012 \quad$ N. meningitidis

Glimåker et al., $2016 \quad$ N. meningitidis

Glimåker et al., 2016

Charlier et al., 2017
Listeria monocytogenes

Listeria monocytogenes
572 Significantly reduced mortality with the use of adjunctive intravenous steroids. [(6.67\% with and $12.5 \%$ without steroids, $(\mathrm{P}=0.0245)]$.

1,132 Corticosteroid treatment effects in 25 studies showed mortality reduction from $36 \%$ to $29.9 \%$. (RR 0.84, 95\% Cl 0.72 to 0.98).

120 Adjunctive steroids within 4 hours were more likely given to those with delayed cerebral injury (5/ 5, 100\% vs. 43/115, 37.5\%; $p=0.01$ ). Adverse effect of delayed cerebral injury found in a higher prevalence $(4.1 \%)$ in patients with pneumococcal meningitis, associated with adjunctive steroid administration.

848 Significant reduction in severe hearing loss with dexamethasone treatment in children (combined odds ratio [OR], 0.31; 95\% confidence interval [Cl], 0.14-0.69).

825 Corticosteroid treatment of across 25 studies showed significant reduction in the rate of hearing loss overall in children from $12 \%$ to $4 \%$ after adjunctive corticosteroid therapy. (RR 0.34, $95 \% \mathrm{Cl}$ 0.20 to 0.59 ) was found.

354 Dexamethasone administered in 17\% of patients from 1998-2002 and 90\% patients in the 20062011 cohort $(p<0.001)$. Rate of arthritis was lower in patients treated with dexamethasone (32 of 258 [12\%] vs. 5 of 96 [5\%], $p=0.046$ ). Adjunctive dexamethasone not found to improve clinical outcomes significantly.

198 Increased survival and recovery without sequelae in corticosteroid-treated compared with noncorticosteroid-treated patients with N. meningitidis (68.6\% vs. 58.1\%). Positive trend is observed, but there is no statistically significant change.

77 Adjunctive steroid therapy showed worsened outcome trend compared to non-steroid-treated patients (48.5\% vs. $40.0 \%)$.

818 Higher mortality in patients when given adjunctive dexamethasone (OR 4.58 [1.50-13.98], $\mathrm{p}=0 \cdot 008)$.
$\mathrm{RCT}$

Observational study

Observational study

Observational study

Observational study Meta analysis

Observational study

Meta analysis

Meta analysis

Observational study

Observational study

Observational study Observational study 
dexamethasone. The demonstrated benefits of adjunctive steroid therapy in reducing pneumococcal meningitis mortality in highincome countries outweigh the possible risks and should continue to be used (Gallegos et al., 2018).

\section{H. influenzae}

The incidence of infection due to $H$. influenzae was reduced significantly in children due to the introduction of the $H$. influenzae type B vaccine. A large 1997 cross-study metaanalysis found a significant reduction in severe hearing loss in $H$. influenzae with dexamethasone treatment in children (McIntyre et al., 1997) (see Table 1). More recent data from a meta analysis of corticosteroid use for the treatment of bacterial meningitis found no significant reductions in mortality across 25 studies in $H$. influenzae meningitis cases treated with adjunctive steroid therapy, but similarly did observe a significant reduction in the rate of hearing loss overall in children with $H$. influenzae meningitis from $12 \%$ to $4 \%$ after adjunctive corticosteroid therapy (Brouwer et al., 2018). Based on the available data, the IDSA guidelines recommend using steroids in children with documented H. influenzae meningitis (Tunkel et al., 2004).

\section{N. meningitidis}

Vaccination has been available since the 1970s against $N$. meningitidis and used on populations identified as high risk. The incidence of meningococcal meningitis in the US decreased from 1997 to 2010 from 0.721 to 0.123 per 100,000 people (RR $0 \cdot 1386$, 95\% CI $0 \cdot 048-0 \cdot 4284)$, which has placed this pathogen close to $H$. influenzae (Castelblanco et al., 2014). Adjunctive dexamethasone does not improve clinical outcomes in meningococcal meningitis but it has been associated with a decrease in arthritis (Heckenberg et al., 2012) (see Table 1). In a study from the Swedish quality registry from 1995-2014, there was trend towards decrease mortality with the use of adjunctive steroids in meningococcal meningitis (Glimåker et al., 2016).

\section{Listeria monocytogenes}

L. monocytogenes most commonly occurs in neonates, adults above the age of 50 years and in patients with cellular immunodeficiency. In the Swedish study, adjunctive steroids showed a trend towards worse outcomes in patients with Listeria meningitis (48.5\% vs. 40.0\%) (Glimåker et al., 2016) (see Table 1). A large prospective study in France of 818 cases of Listeriosis documented a higher mortality in patients with neurolisteriosis when given adjunctive dexamethasone (OR 4.58 [1.50-13.98], $\mathrm{p}=0.008$ ) (Charlier et al., 2017). Adjunctive dexamethasone should be discontinued if meningitis is found not to be caused by $S$. pneumoniae, especially if it is caused by L. monocytogenes (Hasbun, 2019).

\section{ENCEPHALITIS}

Encephalitis is caused by brain tissue inflammation that results in neurological dysfunction from varied etiologies. A nationwide study in the US from 2000-2010, reporting encephalitis hospitalizations, showed unknown etiology in 50\% of patients and viral etiologies (48.2\%), most commonly herpes simplex virus, toxoplasma gondii, and West Nile Virus, with co-morbid HIV present in $7.7 \%$ of hospitalizations. Autoimmune encephalitis among other specified causes was reported in $32.5 \%$ of cases with known etiology (George et al., 2014). The international consortium of encephalitis diagnostic criteria include 1 major criteria: altered mental status for more than $24 \mathrm{~h}$ without alternative diagnosis and several minor criteria: documented fever of $>38^{\circ} \mathrm{C}(100.4 \mathrm{~F})$ within $72 \mathrm{~h}$ of presentation, seizures not attributed to preexisting seizure disorders, the onset of focal neurological deficits, CSF WBC count $>5 /$ cubic $\mathrm{mm}$, new or onset neuroimaging abnormalities consistent with encephalitis presentation, and abnormalities on electroencephalography not due to other causes and consistent with encephalitis presentation (Venkatesan et al., 2013). Possible encephalitis is defined as 1 major criteria with 2 minor criteria; probable encephalitis as 1 major and 3 minor criteria and confirmed if a positive etiology is identified (Encephalitis, Table 3, 2017).

\section{HERPES SIMPLEX VIRUS}

Herpes simplex virus (HSV) is the most common cause of sporadic encephalitis and can manifest with temporal lobe abnormalities leading to personality changes, alterations in mental status, decreased consciousness, seizures, and focal neurological deficits (Hasbun et al., 2018). The peak incidence of herpes simplex encephalitis (HSE) occurs in very young children and adults over the age of 50 years with both sexes equally affected and have an incidence of $2-4 / 1,000,000$ persons. HSE is primarily caused by HSV-1, which accounts for $90 \%$ of HSE in adults and children, while HSV meningitis is commonly caused by HSV-2 (Bradshaw and Venkatesan, 2016). In about one third of 113 confirmed HSV encephalitis cases, the infection was associated with primary infection of HSV-1. In the remaining cases, the virus was associated with the reactivation of latent virus, demonstrated through serologic assessments (Nahmias et al., 1982). High-dose intravenous acyclovir treatment is recommended for 14-21 days in immunocompetent and immunosuppressed patients, respectively. The benefit of acyclovir treatment has been shown through randomized controlled trials to significantly reduce mortality, establishing it as the standard of care for HSV encephalitis (Bradshaw and Venkatesan, 2016). Furthermore, a delay in starting acyclovir therapy has been associated with worse clinical outcomes (Erdem et al., 2015). The use of adjunctive corticosteroid therapy with acyclovir has shown to be beneficial in mouse and pre-clinical models, showing a reduction in the severity of infection, beneficial long-term effects, and no increase in viral burden (Meyding-Lamade et al., 2003). Despite this evidence, there is very limited clinical data evaluating the use of corticosteroid therapy. Furthermore, there is also the potential concern of potentially increasing viral replication. A small nonrandomized retrospective study of 45 patients treated with adjunctive steroids and acyclovir in Japan showed a beneficial 
impact on clinical outcome and reduction in the extent of HSE infection, without inhibition of the antiviral action of acyclovir (Kamei et al., 2005) (see Table 2). The German trial of Acyclovir and Corticosteroids in Herpes-simplex-virus Encephalitis (GACHE) similarly studied the treatment of dexamethasone adjunctive steroid therapy with acyclovir treatment in 41 patients, with 21 patients receiving steroid treatment and 20 receiving a placebo. The small study was stopped prematurely due to slow recruitment and found no significant differences in primary or secondary outcomes between treatment and placebo groups. The primary measured outcome was the functional outcome after 6 months on a modified Rankin scale, and secondary outcomes were the mortality after 6 and 12 months, functional outcomes after 6 and 12 months on the Glasgow outcome scale (GOS), functional outcome after 12 months measured with mRS, quality of life measurements after 6 and 12 months, cranial magnetic resonance imaging findings after 6 months and seizure incidence. This study reinforces the unclear results of corticosteroid adjunctive therapy on HSE and the necessity for larger scale controlled trials (Meyding-Lamadé et al., 2019). Although corticosteroid adjunctive therapy must be studied further as a treatment for HSE, adjunctive corticosteroids are used in practice for patients with increased intracranial pressure and cerebral edema to reduce inflammation.

\section{WEST NILE VIRUS ENCEPHALITIS}

West Nile virus (WNV) is an arthropod-borne infection that is most commonly transmitted by a mosquito bite. The mosquito injects saliva containing the virus into the host dermis with local viral replication in target cells. The virus then migrates to lymph tissue and then disseminates to the CNS via viremia (Colpitts et al., 2012; Hasbun et al., 2018). Incubation periods range from 2 days to 14 days, where $80 \%$ of cases remain asymptomatic, $20 \%$ have a febrile illness presentation, and $1 \%$ present with neuroinvasive disease, which may show aseptic meningitis, encephalitis, or acute flaccid paralysis/myelitis, disrupting the spinal cord (Hasbun et al., 2018). If the virus infiltrates the brain, it commonly infects the basal ganglia, thalamus, and brain stem. Neuronal death, necrosis, and inflammation occur on a microscopic level. Patients presenting with West Nile Encephalitis (WNE) also have chorioretinitis in 50\% of cases (Hasbun et al., 2016). Other common symptoms include fever, altered mentation, fatigue, myalgia, headache, stiff neck, rash, vomiting, and diarrhea. Patients diagnosed with WNE have a mortality rate of $15 \%-18.6 \%$. Currently, no FDA approved treatments vaccine or therapy is approved for WNV infections in humans (Hasbun et al., 2018). Although there are no specific treatments for WNV infections, corticosteroid adjunctive treatment has been used in treatment for and shown rapid improvement effects in a case report of high dose corticosteroid treatment resulting in improvement of a patient from stupor to wakefulness over the course of treatment. The patient was a 71-year-old woman with a WNV infection that rapidly progressed to weakness, encephalitis manifesting with dysphagia and dysarthria, persistent delirium, and stupor. After a 5-day course of steroid treatment she made a rapid improvement to wakefulness. This case study provides the observations of only one patient, so the effect may not be due to the antiinflammatory steroid treatment (Leis and Sinclair, 2019). A study of 228 patients with WNV in Colorado, found no difference in patients with WNE, 17 patients received corticosteroids and 3 died (18\%), whereas 9 of 48 patients who did not receive adjunctive corticosteroid treatment died (19\%) (Bode et al., 2006) (see Table 2). Other case studies and reviews of small cohorts have shown no significant changes for patients treated with adjunctive steroids with WNV infection (Bakri and Kaiser, 2004). Due to paucity of data, the evidence for the use of corticosteroid therapy in the treatment of WNE is still unclear and must be further investigated in large cohorts.

\section{AUTOIMMUNE ENCEPHALITIS}

Autoimmune encephalitis is caused by inflammation from the body's own immune system attacking healthy cells in the brain and spinal cord. Primary autoimmune encephalitis is characterized by immune response directed at cell surface proteins, while paraneoplastic autoimmune encephalitis is a subset associated with tumors and may be the by-product of immune responses to cancerous growth (Hasbun et al., 2017; Hasbun et al., 2018). Autoimmune encephalitis requires clinical criteria of rapid progression in less than 3 months, resulting in neurological debilitation and working memory deficits. Other neurological symptoms include altered level of consciousness, lethargy, personality changes, and other diagnostic findings specific to autoantibodies present in infection. The standard

TABLE 2 | Studies on adjunctive steroid therapy for viral encephalitis.

\begin{tabular}{|c|c|c|c|c|}
\hline Reference & Diagnosis & $\mathbf{N}$ & Primary Findings & $\begin{array}{l}\text { Type of } \\
\text { Study }\end{array}$ \\
\hline Kamei et al., 2005 & Herpes Simplex Virus & 45 & $\begin{array}{l}\text { Effects of adjunctive steroids and acyclovir studied. Beneficial impact on clinical outcome and } \\
\text { reduction in the extent of HSE infection, without inhibition of the antiviral action of acyclovir. }\end{array}$ & $\begin{array}{l}\text { Observational } \\
\text { study }\end{array}$ \\
\hline $\begin{array}{l}\text { Martinez-Torres et al., } \\
2008\end{array}$ & Herpes Simplex Virus & 41 & $\begin{array}{l}\text { Dexamethasone adjunctive steroid therapy with acyclovir versus placebo found no significant } \\
\text { differences in primary or secondary outcomes between groups. }\end{array}$ & $\mathrm{RCT}$ \\
\hline Leis and Sinclair, 2019 & West Nile Virus & 1 & $\begin{array}{l}\text { 71-year-old woman with weakness, encephalitis, dysphagia and dysarthria, persistent delirium, } \\
\text { and stupor improved to wakefulness, after 5-day course of adjunctive steroid treatment. }\end{array}$ & Case report \\
\hline Bode et al., 2006 & West Nile Virus & 228 & $\begin{array}{l}3 / 17 \text { patients with corticosteroids died (18\%), while } 9 / 48 \text { patients who did not receive } \\
\text { adjunctive corticosteroid treatment died (19\%). }\end{array}$ & $\begin{array}{l}\text { Observational } \\
\text { Study }\end{array}$ \\
\hline
\end{tabular}


clinical evaluation of patients for autoimmune encephalitis includes clinical presentation, an MRI of the brain, CSF assessment, and EEG. Autoantibodies detected determine disease pathogenesis and classification within autoimmune encephalitis (Graus et al., 2016; Hasbun et al., 2018). The most frequent clinical syndromes are from anti-N-methyl-D-aspartate receptor (NMDAR) encephalitis, characterized by behavioral and psychiatric differences, seizures, memory deficits, and limbic encephalitis, characterized by confusion, agitation, memory deficits, and seizures (Nosadini et al., 2015) (see Table 3). Treatment of acute autoimmune encephalitis includes immunotherapy, addressing underlying detected malignancies, and treatment of associated sequelae. Autoimmune encephalitis, characterized by antibodies attacking cell surface proteins, responds to antibody-directed therapy such as intravenous immunoglobulin and plasmapheresis. This treatment is accompanied by the administration of corticosteroids intravenously, such as methyl prednisone. Second-line therapy in the acute phase is rituximab and cyclophosphamide. In the maintenance phase mycophenolate, azathioprine, rituximab, cyclophosphamide, corticosteroids, and intravenous immunoglobulin are administered (Nosadini et al., 2015; Hasbun et al., 2018). Corticosteroids are incorporated into first and second-line immunotherapy for autoimmune encephalitis in conjunction with intravenous immunoglobulin administration. In a review of studies on the treatment of anti-LG1 autoantibody encephalitis, the addition of corticosteroids was shown to have a significant association with the cessation of faciobrachial dystonic seizures (FBDS) in $30 \%$ of patients by the first week, and $60 \%$ within 2 months. In second-line immune therapy, the most consistent reductions in seizure frequency and mRS score for neurologic disability improvement were associated with steroid treatment (Shin et al., 2013; Nosadini et al., 2015; Shin et al., 2018). The accepted first-line therapies include adjunctive corticosteroid treatment, intravenous immunoglobin, plasma exchange, and immune-adsorption, which have consistently shown positive results in treatment through case studies and systematic review. Corticosteroid therapy in autoimmune encephalitis is used to broadly inhibit the inflammatory response, but possesses little targeted therapy and is associated with systemic side effects, such as the aggravation of psychiatric symptoms like depression, insomnia, agitation, and psychosis, and neurotoxic effects through the potential to induce neurodegeneration with chronic exposure, making other lines of treatment more effective in combination (Shin et al., 2018). More research must be conducted to determine the optimization of corticosteroid use in conjunction with alternative therapies to maximize clinical benefits and further research on steroid-sparing agents in second-line therapy and long- term maintenance of autoimmune encephalitis.

\section{TUBERCULOSIS}

\section{Initial Therapy}

Tuberculosis (TB) is caused by Mycobacterium tuberculosis and in $85 \%$ of cases it involves the lungs. One of the most common sites of extra pulmonary TB is the CNS (Hasbun et al., 2018). Tuberculosis meningitis is the most common form of CNS tuberculosis and is found in $10 \%-15 \%$ of children $<2$ years old after untreated TB infection and is often misdiagnosed as bacterial meningitis (Hasbun et al., 2018). Tuberculosis meningitis is postulated to occur in two stages. First, bacterial lesions form in the brain or meninges, from the dispersion of bacteria through the bloodstream in early infection, leading to the development of meningitis upon entry into the subarachnoid space. Second, proteins and chemicals from the organism leak into the CSF, eliciting an immune response and intense inflammation at the brain and meninges (Hasbun et al, 2018). Bacille Calmette-Guerin (BCG) vaccines can prevent up to $50 \%-80 \%$ of $\mathrm{TB}$ meningitis cases, but effectiveness varies with available strains of BCG. The vaccination rates do not meet optimal standards in many areas still (Hasbun et al., 2018). The adjunctive treatment of corticosteroids has been employed to reduce inflammation in tuberculosis meningitis. A randomized, double blind, controlled trial in Vietnam of 545 patients with TB meningitis over 14 years of age with and without human immunodeficiency virus (HIV) infection, studied the use of dexamethasone steroid treatments effects. Treatment with dexamethasone was associated with reduced risk of death and significantly fewer adverse events than in placebo groups, which was consistent across various grades of disease severity and HIV status, providing strong evidence for corticosteroid adjunctive therapy to improve survival in patients over age 14 years with TB meningitis (Thwaites et al., 2004) (see Table 4). In a meta analysis of published RCTs of corticosteroid treatment used in TB meningitis, six randomized controlled trials totaling 990 patients were identified, one of which included HIV infected patients. In all studies, the use of corticosteroid adjunctive treatment reduced mortality rates. These results were significant in four of the documented studies. Approximately 39\%-73\% of the patients across the six trials were severely ill with stage 2 disease (drowsy with focal neurologic deficits) and 23\%-56\% with stage 3 disease (coma). Faster defervescence, fewer complications of tuberculomas, and fewer clinical complications from antituberculosis medications were documented as well (McGee and

TABLE 3 | Studies on Adjunctive Steroid Therapy for Autoimmune Encephalitis.

\begin{tabular}{|c|c|c|c|c|}
\hline Reference & Pathogen & $\mathbf{N}$ & Primary Findings & Type of Study \\
\hline Shin et al., 2013 & $\begin{array}{l}\text { Autoimmune } \\
\text { Encephalitis }\end{array}$ & 14 & $\begin{array}{l}\text { Patients with LG1 antibodies as a target protein treated with steroids alone were more likely to relapse } \\
\text { and had less favorable outcomes than those treated with steroids and intravenous immunoglobins (IVIG). }\end{array}$ & Case Series \\
\hline Nosadini et al., 2015 & $\begin{array}{l}\text { Autoimmune } \\
\text { Encephalitis }\end{array}$ & 1,390 & $\begin{array}{l}\text { Corticosteroids treatment associated with cessation of FBDS (faciobrachial dystonic seizures) within } 1 \\
\text { week in } 30 \%(3 / 10) \text { of patients, and within } 2 \text { months in } 60 \%(6 / 10) . \text { mRS improvement consistently } \\
\text { associated with corticosteroids second-line immune therapy. }\end{array}$ & Meta analysis \\
\hline
\end{tabular}


TABLE 4 | Studies and Significant Findings on Adjunctive Steroid Therapy for Tuberculosis Meningitis Treatment.

\begin{tabular}{|c|c|c|c|c|}
\hline Reference & Pathogen & $\mathbf{N}$ & Primary Findings & Type of Study \\
\hline Thwaites et al., 2004 & $\begin{array}{l}\text { Mycobacterium } \\
\text { tuberculosis }\end{array}$ & 545 & $\begin{array}{l}\text { Effects of dexamethasone steroid treatments in patients over } 14 \text { years of age with and without HIV } \\
\text { infection. Dexamethasone treatment was associated with reduced risk of death (relative risk, } 0.69 \text {; } \\
95 \text { percent confidence interval, } 0.52 \text { to } 0.92 ; P=0.01 \text { ) and significantly fewer adverse events than in } \\
\text { placebo groups ( } 26 \text { of } 274 \text { patients vs. } 45 \text { of } 271 \text { patients, } P=0.02 \text { ), consistent across various } \\
\text { grades of disease severity and HIV status. }\end{array}$ & $\mathrm{RCT}$ \\
\hline $\begin{array}{l}\text { McGee and } \\
\text { Hirschmann, } 2008\end{array}$ & $\begin{array}{l}\text { Mycobacterium } \\
\text { tuberculosis }\end{array}$ & 990 & $\begin{array}{l}\text { Across six randomized controlled studies, corticosteroid adjunctive treatment reduced mortality } \\
\text { rates and the differences were significant in } 4 / 6 \text { of the trials. Faster defervescence, fewer } \\
\text { complications of tuberculomas, and fewer clinical complications from anti-tuberculosis medications } \\
\text { documented. }\end{array}$ & Meta analysis \\
\hline Murdoch et al., 2007 & $\begin{array}{l}\text { Mycobacterium } \\
\text { tuberculosis }\end{array}$ & - & $\begin{array}{l}\text { Adjunctive corticosteroid therapy effective in some cases of TB-IRIS for anti-inflammatory purposes } \\
\text { in alleviating symptoms. Corticosteroids effectiveness often anecdotal, requiring larger systematic } \\
\text { studies worldwide. }\end{array}$ & Meta analysis \\
\hline Meintjes et al., 2010 & $\begin{array}{l}\text { Mycobacterium } \\
\text { tuberculosis }\end{array}$ & 110 & $\begin{array}{l}\text { Patients with TB-IRIS treated with prednisone }(1.5 \mathrm{mg} / \mathrm{kg} / \text { day for } 2 \text { weeks then } 0.75 \mathrm{mg} / \mathrm{kg} / \text { day for } 2 \\
\text { weeks) for more rapid improvement in the steroid-treated group arm at } 2 \text { weeks }(p=0.001) \text { and } 4 \\
\text { weeks }(p=0.03) \text {, and reduced the number of days hospitalized (median cumulative of } 0 \mathrm{vs.} 3 \text { days; } \\
(p=0.009)) \text {. Infections occurred in } 27 \text { participants in the prednisone arm and } 17 \text { in the placebo arm } \\
(p=0.05) \text {, although the majority of infections were mild. }\end{array}$ & $\mathrm{RCT}$ \\
\hline Prasad et al., 2016 & $\begin{array}{l}\text { Mycobacterium } \\
\text { tuberculosis }\end{array}$ & 1,337 & $\begin{array}{l}\text { Across nine trials, use of adjunctive steroids in tuberculosis meningitis (with and without HIV) } \\
\text { reduced deaths by almost one quarter after an 18-month follow up.(RR } 0.75,95 \% \mathrm{Cl} 0.65 \text { to } 0.87 \text { ). } \\
\text { Reduction in the risk of death or disabling residual neurological deficit with corticosteroids (RR 0.80, } \\
95 \% \mathrm{Cl} 0.72 \text { to 0.89; eight trials, } 1314 \text { participants) }\end{array}$ & Meta analysis \\
\hline
\end{tabular}

Hirschmann, 2008). A Cochrane study has also demonstrated over nine trials and 1,337 participants that use of adjunctive steroids in tuberculosis meningitis reduced deaths by almost one quarter after an 18 month follow up. While the former meta-analysis does not indicate outcome differences between stages of TB infection, the Cochrane study shows that the effect of corticosteroids is significantly consistent across all stages of the disease. Analysis also did not show differences in outcome based on HIV status, although the analysis was noted as underpowered (Prasad et al., 2016). CDC guidelines on the treatment of Tuberculosis based off of published treatment results, recommend the addition of corticosteroids in treatment for tuberculosis meningitis for all patients, although data is limited for patients with HIV (American Thoracic Society, CDC, \& Infectious Disease Society of America, 2003; Lewinsohn et al., 2017). Overall, the research shows benefit in reduction of mortality and adverse effects in the use of corticosteroids as an adjunctive treatment in cases of initial therapy for confirmed tuberculosis meningitis.

\section{PARADOXICAL REACTION}

Paradoxical reaction (PR) in tuberculosis is the clinical or radiological worsening of pre-existing $\mathrm{TB}$ or the development of new TB lesions in patients who have received treatment against TB and improved in treatment initially. It affects up to $25 \%$ of patients and can cause significant morbidity especially in CNS tuberculosis (Bloch et al., 2009). The manifestation of PR in TB patients includes neuroimaging abnormalities, altered CSF pictures, and changes in CSF, including lymphatic pleocytosis, and an increase in CSF protein levels. Corticosteroid treatment has been demonstrated to have beneficial effects through case studies (Teoh et al., 1986; Garcia-Monco et al., 2005; Kim and Kim, 2009; Singh et al., 2016). TB related immune reconstitution inflammatory syndrome (IRIS) can also occur in HIV-positive patients after introducing antiretroviral therapy (ART) and can be life threatening. In a meta-analysis of 8 RCTs it was shown that there was a two-fold increase in TB-IRIS in patients treated with ART. In patients with a new diagnosis of TB and a CD4 count of less than $50 / \mathrm{mm}^{3}$, ART within 1-4 weeks of diagnosis improved outcomes. Earlier ART, however, may be associated with more frequent TB-IRIS, so ART therapy is recommended only after 4-6 weeks of diagnosis in patients with HIV-1 TB and higher CD4 counts (Davis et al., 2018). TB related IRIS is more common in adults, occurring in $15.7 \%$ of TB patients within 2 months of ART therapy, and is a frequent complication of ART in resource-limited countries, with up to a $30 \%$ overall mortality rate (Meintjes et al., 2010; Fane et al., 2018; Hasbun et al., 2018). Adjunctive corticosteroid therapy has shown to be effective in some cases of TB-IRIS for anti-inflammatory purposes in alleviating symptoms. The use of corticosteroids has been variable, however, and effectiveness often anecdotal, requiring larger systematic studies worldwide (Murdoch et al., 2007). A randomized double-blind controlled trial of 110 patients in South Africa shows that patients with TB-IRIS were treated with prednisone resulting in more rapid improvement in the steroid-treated group and reduced the number of days hospitalized with no excess of glucocorticoid adverse drug reaction. Glucocorticoid therapy can be effective in treating TBIRIS in severe cases, however, the diagnoses of paradoxical TB-IRIS must be correct, and alternate diagnoses must be eliminated completely, due to the existing possibility of adverse effects from steroid adjunctive treatment (Meintjes et al., 2010).

\section{CRYPTOCOCCAL MENINGITIS}

\section{Initial Infection}

Cryptococcal meningitis (CM) is an infection of the meninges due to Cryptococcus neoformans or Cryptococcus gatti, which is less common and thought to cause disease more often in immunocompetent 
patients (Hasbun et al., 2018). CM is the most prevalent cause of meningitis in populations with high HIV prevalence, particularly as seen in studies conducted in countries and populations with high HIV prevalence in sub-Saharan Africa. It is correlated with a lower CD4 + count in HIV patients (Jarvis et al., 2010; Rajasingham et al., 2015). CM associated with HIV infection causes over 600,000 deaths per year worldwide, with little improvement in treatment. A doubleblind randomized controlled trial studied the use of adjunctive dexamethasone steroid therapy in combination with antifungal treatments, amphotericin B and fluconazole, for six weeks in 451 adult patients with $\mathrm{CM}$ in Vietnam, Thailand, Indonesia, Laos, Uganda, and Malawi. The trial was stopped prior to completion for safety concerns. A mortality rate of $47 \%$ with dexamethasone treatment and $41 \%$ in the placebo group at 10 weeks was originally observed, but after 6 months of treatment the corticosteroid treatment group had increased mortality of $57 \%$ in comparison to the placebo of $47 \%$. The percentage of patients with disability by 10 weeks of treatment was higher in dexamethasone-treated groups and dexamethasone-treated groups showed more clinically adverse outcomes such as the increased prevalence of grade 3 or 4 infection, renal events, and cardiac events (Beardsley et al., 2016) (see Table 5). Based on this study, adjunctive steroids should be avoided in Cryptococcal meningitis.

\section{Immune Reconstitution Syndrome (IRIS)}

IRIS occurs when immunological recovery after infection contributes to worsening disease in the long term. In HIV patients, after ART and successful immune restoration, inflammatory responses and worsened opportunistic infection has been observed. IRIS is clinically characterized by localized and systemic inflammatory response during invasive fungal infection (Singh and Perfect, 2007). CM-IRIS is seen in HIV patients with CM either as: a) paradoxical IRIS, meaning a relapse of infection after antifungal therapy and initiation of ART or b) as unmasking IRIS, when CM is developed after starting ART and an underlying, previously undiagnosed infection resurfaces. IRIS is developed in 30\% HIV and CM co-infected patients who initiate ART. It is increased in individuals with high CSF fungal burdens in initial CM infection and in those who do not clear infection prior to the initiation of antiretroviral treatments (Shelburne et al., 2005; Fane et al., 2018; Hasbun et al., 2018). Systemic corticosteroids

TABLE 5 | Studies and Significant Findings on Adjunctive Steroid Therapy for Fungal and Parasitic CNS Infection.

\begin{tabular}{|c|c|c|c|c|}
\hline Reference & Pathogen & $\mathbf{N}$ & Primary Findings & $\begin{array}{l}\text { Type of } \\
\text { Study }\end{array}$ \\
\hline Murdoch et al., 2007 & C. neoformans or C. gatti & - & $\begin{array}{l}\text { Across small studies and anecdotal benefits, it is reasonable to administer systemic } \\
\text { corticosteroids to alleviate unresponsive inflammatory effects. }\end{array}$ & Meta analysis \\
\hline Beardsley et al., 2016 & C. neoformans or C. gatti & 451 & $\begin{array}{l}\text { Studied use of adjunctive dexamethasone steroid therapy in combination with antifungal } \\
\text { treatments, amphotericin B and fluconazole, for six weeks. Mortality rate of } 47 \% \text { with } \\
\text { dexamethasone treatment and } 41 \% \text { in the placebo group ( } 10 \text { weeks) and } 57 \% \text { mortality } \\
\text { with dexamethasone treatment in comparison to the placebo of } 47 \% \text { ( } 6 \text { months). Disability } \\
\text { and adverse effects higher in dexamethasone-treated groups by } 10 \text { weeks of treatment. }\end{array}$ & RCT \\
\hline Perfect et al., 2018 & C. neoformans or C. gatti & - & $\begin{array}{l}\text { In CM-IRIS major complications, such as CNS inflammation with increased intracranial } \\
\text { pressure, corticosteroids (0.5-1.0 mg/kg per day of prednisone equivalent) should be } \\
\text { administered and possibly dexamethasone at higher doses for severe CNS signs and } \\
\text { symptoms, with a concomitant antifungal regimen. }\end{array}$ & Meta analysis \\
\hline Slom et al., 2002 & A. cantonensis & 12 & $\begin{array}{l}\text { Repeated lumbar punctures and corticosteroid therapy led to improvement of severe } \\
\text { headaches and intracranial pressure decrease. }\end{array}$ & Case series \\
\hline Maretic et al., 2009 & A. cantonensis & 11 & $\begin{array}{l}\text { Data supports use of albendazole and mebendazole steroid treatment. Anthelmintic } \\
\text { treatment administration not recommended without adjunctive steroid treatment. }\end{array}$ & Case series \\
\hline Wang et al., 2012 & A. cantonensis & - & Small outbreak data supports corticosteroids treatment in combination with anthelmintics & Meta analysis \\
\hline $\begin{array}{l}\text { Pereira-Chioccola } \\
\text { et al., } 2009\end{array}$ & Toxoplasma gondii & - & $\begin{array}{l}\text { Cases of diffuse encephalitis and expansive lesions with a mass effect in the brain are } \\
\text { recommended adjunctive corticosteroid therapy. }\end{array}$ & Meta analysis \\
\hline Sonneville et al., 2012 & Toxoplasma gondii & 100 & $\begin{array}{l}\text { Analyzed patients with HIV and the outcome of adjunctive steroid therapy. With the use of } \\
\text { pyrimethamine-sulfadiazine treatment, adjunctive steroids to treat cerebral edema } \\
\text { associated with focal lesions are safe but not associated with better neurologic outcomes. }\end{array}$ & $\begin{array}{l}\text { Observational } \\
\text { Study }\end{array}$ \\
\hline Singhi et al., 2004 & Taenia solium & 133 & $\begin{array}{l}\text { Disappearance of lesions at 3-month follow up higher }(62.9 \%) \text { in corticosteroid treatment } \\
\text { with albendazole group compared to albendazole treatment alone }(52.6 \%) \text {. Children in the } \\
\text { corticosteroid group had significantly higher seizure recurrence while on AEDs. }\end{array}$ & $\mathrm{RCT}$ \\
\hline $\begin{array}{l}\text { Kishore and Misra, } \\
2007\end{array}$ & Taenia solium & 100 & $\begin{array}{l}\text { Higher resolution in group that received prednisone alone }(68.1 \%) \text { compared to treatment } \\
\text { with antiepileptic monotherapy }(60.9 \%)(p<0.05)\end{array}$ & $\mathrm{RCT}$ \\
\hline White et al., 2018 & Taenia solium & - & $\begin{array}{l}\text { Guidelines for the treatment of Neurocysticercosis in America. Corticosteroids should be } \\
\text { used in viable parenchymal NCC for reduction in seizure frequency.Corticosteroids should } \\
\text { be given with antiparasitic with single enhancing lesion NCC. Corticosteroids should be } \\
\text { used, while avoiding antiparasitic treatment with cysticercal encephalitis (with diffuse } \\
\text { cerebral edema). Corticosteroids should not be routinely used for calcified parenchymal } \\
\text { NCC with or without perilesional edema due to the development of calcifications with } \\
\text { perilesional edema in some cases }\end{array}$ & Meta analysis \\
\hline
\end{tabular}


have been administered to alleviate inflammation and resulted in positive response through case studies (King et al., 2002; Murdoch et al., 2007). The particular role of adjunctive steroid treatment remains unclear in IRIS, although it has been considered reasonable to administer corticosteroids only in severe cases of unresponsive inflammation (Sharma and Soneja, 2011; Fane et al., 2018).

\section{Angiostrongylus cantonensis}

Angiostrongylus is a parasitic nematode causing severe CNS diseases in humans. A. cantonensis from larval invasion causes eosinophilic meningitis as the primary clinical manifestation of the disease. Infection occurs from consuming infected intermediate hosts or vegetables contaminated by these hosts (Martins et al., 2015). Outbreaks in human angiostrongyliasis have been reported in endemic regions such as the Pacific Islands, Southeast Asia, the Caribbean Islands, and Brazil. Treatment includes corticosteroids in combination with anthelmintics (Wang et al., 2012) (see Table 5). In a retrospective cohort study, out of 12 hospitalized adults who had traveled to Jamaica and were diagnosed with eosinophilic meningitis, repeated lumbar punctures and corticosteroid therapy led to the improvement of severe headaches in two out of three patients, and intracranial pressure decrease in all three (Slom et al., 2002). A review of case studies demonstrates data favoring the use of antiparasitic (albendazole or mebendazole) and steroid treatment, although anthelmintic administration was not recommended without steroid treatment (Maretic et al., 2009). Anthelmintic treatment is recommended only in early stages of infection, through demonstrated CNS and pulmonary complications when administered beyond 3 weeks of treatment. When anthelmintic treatment is effective later in infection, it kills viable larvae, suspending them in the CNS with negative clinical consequences. Similar effects of delayed resolution of inflammation and disposal of the worm carcass, causing further damage, is noted with prolonged corticosteroid therapy (Prociv and Turner, 2018). Corticosteroid therapy may be beneficial in early treatment, with recommendations to apply the treatment in severe cases, although data is limited in large clinical trials to demonstrate significance and effectiveness in treatment.

\section{Toxoplasma gondii}

Toxoplasma gondii, a single-celled parasite found across the world, causes toxoplasmosis infection. Toxoplasmosis is one of the most common human infections. CNS infection by T. gondii causes toxoplasma encephalitis, which is the most common cause of brain mass lesions in HIV infected patients, causing high mortality and morbidity (Vidal, 2019). T. gondii causes latent infection in $10 \%-90 \%$ of the world's population, but clinical presentation otherwise often includes brain abscess and diffuse encephalitis or ventriculitis (Marra, 2018). In patients with HIV, single or multiple ring-enhancing lesions on CT or MRI scans suggest toxoplasma encephalitis in the setting of a positive Toxoplasma IGG. Adjunctive corticosteroid therapy should be considered in patients with brain abscesses with significant cerebral edema (Pereira-Chioccola et al., 2009) (see Table 5). The most effective treatment for CNS toxoplasmosis is sulfadiazine and pyrimethamine. Steroid treatment is not recommended unless disproportionate cytotoxic edema is displayed and life threatening. In the case of brain abscess, steroids effectively reduce brain edema, but reduce the effectiveness of host defense processes as well (Muzumdar et al., 2011; Patel and Clifford, 2014). There is no large study demonstrating the efficacy of adjunctive steroid therapy in HIV related toxoplasmosis. Steroid administration is recommended only when lesions due to toxoplasmosis have developed significant mass effect or diffuse brain edema is seen, although the significant benefit of adjunctive steroid therapy in mortality, even in the treatment of cerebral edema, has not been demonstrated in a large cohort (Haverkos, 1987; Rothova et al., 1989; Pereira-Chioccola et al., 2009; Sonneville et al., 2012; Vidal, 2019). Corticosteroids can be used in severe abscess related edema or cases of clinically significant mass effect, with early animal studies showing a reduction in the penetration of antimicrobials into the abscess (Patel and Clifford, 2014).

\section{NEUROCYSTICERCOSIS}

Neurocysticercosis (NCC) is the most common parasitic disease of the CNS in humans, caused by the larval stage of the Taenia solium tapeworm. The parasites, once ingested, reach mature size at 3 months, and are established as larval cysts in the tissue, causing single lesions or several lesions in some cases (Garcia et al., 2010). NCC is the single most common cause of acquired epileptic episodes in the developing world, which is the most common presentation of parenchymal NCC (Singhi et al., 2004; Garcia et al., 2010). The Infectious Disease Society of America (IDSA) strongly recommends adjuvant corticosteroid therapy with antiparasitics for anti-inflammatory purposes in patients with viable parenchymal neurocysticercosis (NCC). Steroid therapy has been associated with fewer seizures, although optimal doses have not yet been defined. For single enhancing lesions due to NCC, corticosteroids concomitant with antiparasitic treatment is also strongly recommended, due to data on worsening symptoms with antiparasitic treatment alone (Singhi et al., 2004; White et al., 2018). In the case of calcified parenchymal NCC with or without perilesional edema, corticosteroid therapy is not routinely recommended. In cysticercal encephalitis with diffuse cerebral edema, the IDSA recommends that corticosteroid treatment is administered, without the use of antiparasitic drugs, because antiparasitic treatment is associated with worsening edema. The guidelines show that evidence from large case series and overall evaluation points to antiparasitic treatment with steroid therapy, over antiparasitic treatment alone, as antiparasitic drugs have been shown to worsen the symptoms of NCC (White et al., 2018). Corticosteroids are the primary treatment for chronic cysticercosis arachnoiditis or encephalitis NCC (Garcia et al., 2010). Due to the varying nature of antiparasitic treatment in combination with adjunctive corticosteroid therapy across different presentations of NCC, treatment of NCC with must be individualized (Singhi et al., 2004). 
TABLE 6 | Studies on adjunctive steroids use for the treatment of bacterial brain abscess.

\begin{tabular}{|c|c|c|c|c|}
\hline Reference & Pathogen & $\mathbf{N}$ & Primary Findings & $\begin{array}{l}\text { Type of } \\
\text { Study }\end{array}$ \\
\hline $\begin{array}{l}\text { Muzumdar et al., } \\
2011\end{array}$ & Brain Abscess & 289 & $\begin{array}{l}\text { Steroid administration is not recommended unless life-threatening issues of cytotoxic edema. } \\
\text { Intravenous were steroids administered for } 15 \text { patients, who presented with significant perifocal } \\
\text { edema. Steroid therapy was tapered over } 2 \text { weeks and edema was markedly reduced with resolution } \\
\text { of the abscess cavity after steroid therapy. }\end{array}$ & $\begin{array}{l}\text { Observational } \\
\text { Study }\end{array}$ \\
\hline $\begin{array}{l}\text { Patel and Clifford, } \\
2014\end{array}$ & $\begin{array}{l}\text { Bacterial Brain } \\
\text { Abscess }\end{array}$ & - & $\begin{array}{l}\text { Steroid administration is not recommended unless severe abscess related edema has led to clinically } \\
\text { significant mass effect. Corticosteroid therapy may reduce antimicrobial penetration into the abscess. }\end{array}$ & Meta analysis \\
\hline
\end{tabular}

\section{BACTERIAL BRAIN ABSCESS}

Brain abscess is a focal infection of the brain with localized inflammation of the cerebrum. Bacteria is responsible for over $95 \%$ of all brain abscesses, entering the brain through the contiguous spread, hematogenous dissemination, or as a consequence of distant infectious foci in other organs. (Patel and Clifford, 2014; Sonneville et al., 2017). The incidence of bacterial brain abscess is around 0.3-0.9/100,000 inhabitants per year in developed countries (Sonneville et al., 2017). Clinical symptoms of bacterial brain abscess include fever, focal neurological deficits, seizures, and altered consciousness. In addition to antibacterial treatment that is recommended upon identification of the condition, patients with warning signs of brain herniation can be placed on a short course of adjunctive steroids (Sonneville et al., 2017). Steroid administration is not typical to bacterial brain abscess and is not recommended unless life-threatening issues of cytotoxic edema are present and have led to clinical mass effect (Miranda et al., 2013). In these cases, the adjunctive corticosteroid therapy may be effective in reducing antimicrobial penetration into the abscess. Although steroid therapy is effective due to anti-inflammatory properties in the case of brain edema, the host's defense mechanisms may be disrupted. Steroids have also been shown to inhibit collagen capsule formation, which may inhibit a key mechanism for leucocyte travel in the body's defense systems (Muzumdar et al., 2011; Patel and Clifford, 2014) (see Table 6).

\section{CONCLUSION}

Adjunctive steroids therapy has proven effective to improved outcomes in some cases of CNS infection, although in others administration of steroid therapy can be detrimental. Critical

\section{REFERENCES}

American Thoracic Society, CDC, \& Infectious Disease Society of America (2003). Treatment of Tuberculosis. Am. J. Respir. Crit. Care Med. 167, 603-662.

Archibald, L. K., and Quisling, R. G. (2013). Central Nervous System Infections. Textbook Neurointensive Care 1, 427-517. doi: 10.1007/978-14471-5226-2_22

Bakri, S., and Kaiser, P. (2004). Ocular manifestations of West Nile virus. Curr. Opin. Ophthamol. 15, 537-540. doi: 10.1097/01.icu.0000143687.45232.f1

Barnes, P. J. (2006). How corticosteroids control inflammation: Quintiles Prize Lecture 2005. Br. J. Pharmacol. 148 (3), 245-254. doi: 10.1038/sj.bjp.0706736 evaluation of the presenting infection and point of administration is necessary for optimal therapeutic use as indicated through the review. Adjunctive steroids are effective in reducing inflammation and improving clinical outcomes in some causes of meningitis such as S. pneumoniae (mortality), $\mathrm{H}$. influenzae (hearing loss), $N$. meningitidis (arthritis), and M. tuberculosis (mortality). Even though the use of adjunctive steroids is an essential therapy of autoimmune encephalitis, its use in viral encephalitis is unclear as there are limited studies. Steroids are also used in A. cantonensis meningitis and in brain abscesses caused by bacteria or by toxoplasmosis when associated with significant mass effect or cerebral edema. Adjunctive corticosteroid therapy is also consistently recommended in neurocysticercosis with cerebral edema. Adjunctive corticosteroids are also used in IRIS treatment to alleviate inflammation in severe cases. The use of corticosteroid therapy can also be detrimental as in L. monocytogenes or CM so an accurate, prompt diagnosis is key. Overall, data for the use adjunctive steroids in several CNS infections (e.g., HSV, WNV, etc.) are limited and future studies should explore the utility of steroids in larger-scale studies.

\section{AUTHOR CONTRIBUTIONS}

$\mathrm{RH}$ conceived the general idea and provided critical revision and final approval of the manuscript. SG conducted the literature review and wrote the draft manuscript. All authors contributed to the article and approved the submitted version.

\section{FUNDING}

The Grant A Starr Foundation supported this work.

Beardsley, J., Wolbers, M., Kibengo, F. M., Ggayi, A. B. M., Kamali, A., Cuc, N. T. K., et al. (2016). Adjunctive Dexamethasone in HIV-Associated Cryptococcal Meningitis. N. Engl. J. Med. 374 (6), 543-554. doi: 10.1056/NEJMoa1509024

Bloch, S., Wickremasinghe, M., Wright, A., Rice, A., Thompson, M., and Kon, O. M. (2009). Paradoxical reactions in non-HIV tuberculosis presenting as endobronchial obstruction. Eur. Respir. Rev. 18 (114), 295-298. doi: 10.1183/ 09059180.00003709

Bode, A. V., Sejvar, J. J., Pape, W. J., Campbell, G. L., and Marfin, A. A. (2006). West Nile Virus Disease: A Descriptive Study of 228 Patients Hospitalized in a 4-County Region of Colorado in 2003. Clin. Infect. Dis. 42 (9), 1234-1240. doi: $10.1086 / 503038$ 
Bradshaw, M. J., and Venkatesan, A. (2016). Herpes Simplex Virus-1 Encephalitis in Adults: Pathophysiology, Diagnosis, and Management. Neurotherapeutics 13 (3), 493-508. doi: 10.1007/s13311-016-0433-7

Brouwer, M. C., Heckenberg, S. G. B., de Gans, J., Spanjaard, L., Reitsma, J. B., and van de Beek, D. (2010). Nationwide implementation of adjunctive dexamethasone therapy for pneumococcal meningitis. Neurology 75 (17), 1533-1539. doi: 10.1212/WNL.0b013e3181f96297

Brouwer, M., McIntyre, P., Prasad, K., and van de Beek, D. (2018). Corticosteroids for acute bacterial meningitis (Review). Cochrane Database Syst. Rev. 9. doi: 10.1002/14651858.CD004405.pub5

Castelblanco, R. L., Lee, M. J., and Hasbun, R. (2014). Epidemiology of bacterial meningitis in the USA from 1997 to 2010: A population-based observational study. Lancet Infect. Dis. 14 (9), 813-819. doi: 10.1016/S1473-3099(14)70805-9

Charlier, C., Perrodeau, É, Leclercq, A., Cazenave, B., Pilmis, B., Henry, B., et al. (2017). Clinical features and prognostic factors of listeriosis: the MONALISA national prospective cohort study. Lancet Infect. Dis. 17 (5), 10. doi: 10.1016/ S1473-3099(16)30521-7

Colpitts, T. M., Conway, M. J., Montgomery, R. R., and Fikrig, E. (2012). West Nile virus: Biology, transmission, and human infection. Clin. Microbiol. Rev. 25 (4), 635-648. doi: 10.1128/CMR.00045-12

Coyle, P. K. (1999). Glucocorticoids in Central Nervous System Bacterial Infection. Arch. Neurol. 56 (7), 796-801. doi: 10.1001/archneur.56.7.796

Dando, S. J., Mackay-Sim, A., Norton, R., Currie, B. J., St John, J. A., Ekberg, J. A., et al. (2014). Pathogens penetrating the central nervous system: infection pathways and the cellular and molecular mechanisms of invasion. Clin. Microbiol. Rev. 27 (4), 691-726. doi: 10.1128/CMR.00118-13

Davis, A., Meintjes, G., and Wilkinson, R. J. (2018). Treatment of Tuberculous Meningitis and Its Complications in Adults. Curr. Treat Options Neurol. 20 (3), 5. doi: 10.1007/s11940-018-0490-9

de Gans, J., and van de Beek, D. (2002). Dexamethasone In Adults With Bacterial Meningitis. N. Engl. J. Med. 346 (13), 957-966. doi: 10.1056/NEJMoa021334

Dorsett, M., and Liang, S. Y. (2016). Diagnosis and Treatment of Central Nervous System Infections in the Emergency Department. Emergency Med. Clinics North Am. 34 (4), 917-942. doi: 10.1016/j.emc.2016.06.013

Encephalitis, Table 3 (2017). Johns Hopkins ABX Guide (Johns Hopkins Guide: The Johns Hopkins University). Available at: https://www.hopkinsguides.com/ hopkins/view/Johns_Hopkins_ABX_Guide/540639/all/Encephalitis:Table_3. Retrieved October 17, 2020.

Engelen-Lee, J. Y., Brouwer, M. C., Aronica, E., and van de Beek, D. (2018). Delayed cerebral thrombosis complicating pneumococcal meningitis: An autopsy study. Ann. Intensive Care 8 (1), 20. doi: 10.1186/s13613-0180368-8

Erdem, H., Cag, Y., Ozturk-Engin, D., Defres, S., Kaya, S., Larsen, L., et al. (2015). Results of a Multinational Study Suggest the Need for Rapid Diagnosis and Early Antiviral Treatment at the Onset of Herpetic Meningoencephalitis. Antimicrob. Agents Chemother. 59 (6), 3084-3089. doi: 10.1128/AAC.05016-14

Erdem, H., Inan, A., Guven, E., Hargreaves, S., Larsen, L., Shehata, G., et al. (2017). The burden and epidemiology of community-acquired central nervous system infections: a multinational study. Eur. J. Clin. Microbiol. Infect. Dis. 36 (9), 1595-1611. doi: 10.1007/s10096-017-2973-0

Fane, M., Mustapha, S., Chakib, A., K, M., and Filali, L. (2018). HIV and Immune Reconstitution Inflammatory Syndrome (HIV-IRIS ). J. Infect. Dis. Pathog. 1 (2), 1-8.

Fitch, M. T., and van de Beek, D. (2008). Drug Insight: steroids in CNS infectious diseases-new indications for an old therapy. Nat. Clin. Pract. Neurol. 4 (2), $97-$ 104. doi: $10.1038 /$ ncpneuro0713

Gallegos, C., Tobolowsky, F., Nigo, M., and Hasbun, R. (2018). Delayed Cerebral Injury in Adults With Bacterial Meningitis: A Novel Complication of Adjunctive Steroids? Crit. Care Med. 46 (8), e811-e814. doi: 10.1097/ CCM.0000000000003220

Garcia-Monco, J., Ferreira, E., and Gomex-Belderrain, M. (2005). The therapeutic paradox in the diagnosis of tuberculous meningitis. Neurology. 65 (12), 19911992. doi: 10.1212/01.wnl.0000188885.31724.07

García, H. H., Gonzalez, A. E., Rodriguez, S., Tsang, V. C., Pretell, E. J., Gonzales, I., et al. (2010). Neurocysticercosis: unraveling the nature of the single cysticercal granuloma. Neurology 75 (7), 654-658. doi: 10.1212/WNL.0b013e 3181ed9eae
George, B. P., Schneider, E. B., and Venkatesan, A. (2014). Encephalitis Hospitalization Rates and Inpatient Mortality in the United State-2010. PLoS One 9 (9), e104169. doi: 10.1371/journal.pone.0104169

Glimåker, M., Brink, M., Naucler, P., and Sjölin, J. (2016). Betamethasone and dexamethasone in adult community-acquired bacterial meningitis: a quality registry study from 1995 to 2014. Clin. Microbiol. Infect. 22 (9), 814.e1-814.e7. doi: 10.1016/j.cmi.2016.06.019

Graus, F., Titulaer, M., Balu, R., and Al, E. (2016). A clinical approach to diagnosis of autoimmune encephalitis.. Lancet Neurology 15 (4), 391-404. doi: 10.1016/ S1474-4422(15)00401-9

Hasbun, R., Garcia, M. N., Kellaway, J., Baker, L., Salazar, L., Woods, S. P., et al. (2016). West nile virus retinopathy and associations with long term neurological and neurocognitive sequelae. PLoS One 11 (3), 1-10. doi: 10.1371/journal.pone.0148898

Hasbun, R., Rosenthal, N., Balada-Llasat, J. M., Chung, J., Duff, S., Bozzette, S., et al. (2017). Epidemiology of Meningitis and Encephalitis in the United State2014. Clin. Infect. Dis. 65 (3), 359-363. doi: 10.1093/cid/cix319

Hasbun, R., Hammadi, A. A., Aurpibul, L., and Al, E. (2018). Meningitis and encephalitis: Management and Prevention Challenges (Switzerland AG: Springer Nature). doi: 10.5005/jp/books/14182_10

Hasbun, R. (2019). Update and advances in community acquired bacterial meningitis. Curr. Opin. Infect. Dis. 32 (3), 233-238. doi: 10.1097/QCO. 0000000000000543

Haverkos, H. (1987). Assessment of therapy for toxoplasma encephalitis. Am. $J$. Med. 82, 907-914. doi: 10.1016/0002-9343(87)90151-3

Heckenberg, S., Brouwer, M., van der Ende, A., and van de Beek, D. (2012). Adjunctive dexamethasone in adults with meningococcal meningitis. Neurology 79 (15), 1563-1569. doi: 10.1212/WNL.0b013e31826e2684

Hoffman, O., and Weber, J. R. (2009). Pathophysiology and treatment of bacterial meningitis. Ther. Adv. Neurol. Disord. 2 (6), 401-412. doi: 10.1177/ 1756285609337975

Jarvis, J. N., Meintjes, G., Williams, A., Brown, Y., Crede, T., and Harrison, T. S. (2010). Adult meningitis in a setting of high HIV and TB prevalence: Findings from 4961 suspected cases. BMC Infect. Dis. 10 (67). doi: 10.1186/1471-2334$10-67$

Kamei, S., Sekizawa, T., Shiota, H., Mizutani, T., Itoyama, Y., Takasu, T., et al. (2005). Evaluation of combination therapy using aciclovir and corticosteroid in adult patients with herpes simplex virus encephalitis. J. Neurol. Neurosurg. Psychiatry 76 (11), 1544-1549. doi: 10.1136/jnnp.2004.049676

Kim, S., and Kim, Y. (2009). Immunologic paradox in the diagnosis of tuberculous meningitis. Clin. Vaccine Immunol. 16 (12), 1847-1849. doi: 10.1128/ CVI.00321-09

King, M., Perlino, C., Cinnamon, J., and Jernigan, J. (2002). Paradoxical recurrent meningitis following therapy of cryptococcal meningitis: an immune reconstitution syndrome after initiation of highly active antiretroviral therapy. Int. J. STD AIDS 13 (10), 724-726. doi: 10.1258/095646202760326516

Kishore, D., and Misra, S. (2007). Short course of oral prednisolone on disappearance of lesion and seizure recurrence in patients of solitary cysticercal granuloma with single small enhancing CT lesion: an open label randomized prospective study. J. Assoc. Phys. India 55, 419-424.

Koyuncu, O. O., Hogue, I. B., and Enquist, L. W. (2013). Virus infections in the nervous system. Cell Host Microbe 13 (4), 379-393. doi: 10.1016/ j.chom.2013.03.010

Leis, A. A., and Sinclair, D. J. (2019). Lazarus effect of high dose corticosteroids in a patient with West Nile virus encephalitis: A coincidence or a clue? Front. Med. 6:81 (APR). doi: 10.3389/fmed.2019.00081

Lewinsohn, D. M., Leonard, M. K., Lobue, P. A., Cohn, D. L., Daley, C. L., Desmond, E., et al. (2017). Official American Thoracic Society/Infectious Diseases Society of America/Centers for Disease Control and Prevention Clinical Practice Guidelines: Diagnosis of Tuberculosis in Adults and Children. Clin. Infect. Dis. 64 (2), el-e33. doi: 10.1093/cid/ciw694

Maretic, T., Perovic, M., Vince, A., Lukas, D., Dekumyoy, P., and Begovac, J. (2009). Meningitis and Radiculomyelitis Caused by Angiostrongylus cantonensis. Clin. Infect. Dis. 15 (6), 996-998. doi: 10.1086/499815

Marra, C. (2018). Central nervous system infection with Toxoplasma gondii. Handbook of Clin. Neurol. 152, 117-122. doi: 10.1016/B978-0-444-638496.00009-8 
Martinez-Torres, F., Menon, S., Pritsch, M., Victor, N., Jenetzky, E., Jensen, K., et al. (2008). Protocol for German trial of Acyclovir and corticosteroids in Herpes-simplex-virus-encephalitis (GACHE): A multicenter, multinational, randomized, double-blind, placebo-controlled German, Austrian and Dutch trial [ISRCTN45122933]. BMC Neurol. 8, 1-10. doi: 10.1186/1471-2377-8-40

Martins, Y. C., Tanowitz, H. B., and Kazacos, K. R. (2015). Central nervous system manifestations of Angiostrongylus cantonensis infection. Acta Tropica 141 (Pt A), 46-53. doi: 10.1016/j.actatropica.2014.10.002

McGee, S., and Hirschmann, J. (2008). Use of corticosteroids in treating infectious diseases. Arch. Internal Med. 168 (10), 1034-1046. doi: 10.1001/ archinte.168.10.1034

McGill, F., Heyderman, R. S., Michael, B. D., Defres, S., Beeching, N. J., Borrow, R., et al. (2016). The UK joint specialist societies guideline on the diagnosis and management of acute meningitis and meningococcal sepsis in immunocompetent adults. J. Infect. 72 (4), 405-438. doi: 10.1016/j.jinf. 2016.01.007

McIntyre, P., Berkey, C., King, S., and Al, E. (1997). Dexamethasone as adjunctive therapy in bacterial meningitis. A meta-analysis of randomized clinical trials since 1988. JAMA 278 (11), 925-931. doi: 10.1001/jama.278.11.925

Meintjes, G., Wilkinson, R. J., Morroni, C., Pepper, D. J., Rebe, K., Rangaka, M. X., et al. (2010). Randomized placebo-controlled trial of prednisone for paradoxical TB-associated IRIS. AIDS 24 (15), 2381-2390. doi: 10.1097/ QAD.0b013e32833dfc68

Meyding-Lamade, U., Oberlinner, C., Rau, P., and Al, E. (2003). Experimental herpes simplex virus encephalitis: a combination therapy of acyclovir and glucocorticoids reduces long-term magnetic resonance imaging abnormalities. J. Neurovirol. 9 (1), 118-125. doi: 10.1080/13550280390173373

Meyding-Lamadé, U., Jacobi, C., Martinez-Torres, F., Lenhard, T., Kress, B., Kieser, M., et al. (2019). The German trial on Aciclovir and Corticosteroids in Herpes-simplex-virus-Encephalitis (GACHE): a multicenter, randomized, double-blind, placebo-controlled trial. Neurol. Res. Pract. 1 (1), 1-9. doi: 10.1186/s42466-019-0031-3

Miranda, H. A., Castellar-Leones, S. M., Elzain, M. A., and Moscote-Salazar, L. R. (2013). Brain abscess: Current management. J. Neurosci. Rural Pract. 4 (Suppl 1), S67-S81. doi: 10.4103/0976-3147.116472

Murdoch, D. M., Venter, W. D. F., Van Rie, A., and Feldman, C. (2007). Immune reconstitution inflammatory syndrome (IRIS): Review of common infectious manifestations and treatment options. AIDS Res. Ther. 4 (9), 1-10. doi: 10.1186/1742-6405-4-9

Muzumdar, D., Jhawar, S., and Goel, A. (2011). Brain abscess: An overview. Int. J. Surg. 9 (2), 136-144. doi: 10.1016/j.ijsu.2010.11.005

Nahmias, A. J., Whitley, R. J., Visintine, A. N., Takei, Y., Alford, C. A. Jr., and Group, C. A. S. (1982). Herpes Simplex Virus Encephalitis: Laboratory Evaluations and Their Diagnostic Significance. J. Infect. Dis. 145 (6), 829836. doi: $10.1093 /$ infdis/145.6.829

NICE UK (2010). "Meningitis (bacterial) and meningococcal septicaemia in under 16s: recognition, diagnosis and management," in NICE Clinical Guideline [CG102], 1-40. Available at: https://www.nice.org.uk/guidance/CG102/ chapter/1-Guidance\#pre-hospital-management-of-suspected-bacterialmeningitis-and-meningococcal-septicaemia.

Nosadini, M., Mohammad, S. S., Ramanathan, S., Brilot, F., and Dale, R. C. (2015). Immune therapy in autoimmune encephalitis: A systematic review. Expert Rev. Neurother. 15 (12), 1391-1419. doi: 10.1586/14737175.2015.1115720

Patel, K., and Clifford, D. B. (2014). Bacterial Brain Abscess. Neurohospitalist 4 (4), 196-204. doi: 10.1177/1941874414540684

Pereira-Chioccola, V., Vidal, J., and Su, C. (2009). Toxoplasma gondii infection and cerebral toxoplasmosis in HIV-infected patients. Future Microbiol. 4, 1363-1379. doi: 10.2217/fmb.09.89

Perfect, J. R., Dismukes, W. E., Dromer, F., Goldman, D. L., John, R., Hamill, R. J., et al. (2018). Clinical Practice Guidelines for the Management of Cryptococcal Disease: 2010 Update by the Infectious Diseases Society of America. Clin. Infect. Dis. 50 (3), 291-322. doi: 10.1086/649858

Prasad, K., Singh, M., and Ryan, H. (2016). Corticosteroids for managing tuberculous meningitis ( Review ). Cochrane Database Syst. Rev. 4, 20082010. doi: 10.1002/14651858.CD002244.pub4.www.cochranelibrary.com

Prociv, P., and Turner, M. (2018). Perspective piece neuroangiostrongyliasis: The "subarachnoid phase" and its implications for anthelminthic therapy. Am. J. Trop. Med. Hyg. 98 (2), 353-359. doi: 10.4269/ajtmh.17-0206
Rajasingham, R., Rhein, J., Klammer, K., Musubire, A., Nabeta, H., Akampurira, A., et al. (2015). Epidemiology of meningitis in an HIV-infected Ugandan cohort. Am. J. Trop. Med. Hyg. 92 (2), 274-279. doi: 10.4269/ajtmh.14-0452

Rothova, A., Buitenhuis, H. J., Meenken, C., Baarsma, G. S., Boen-Tan, T. N., de Jong, P. T., et al. (1989). Therapy of ocular toxoplasmosis. Int. Ophthalmol. 13 (6), 415-419. doi: 10.1007/BF02306491

Scheld, W. M., Dacey, R. G., Winn, H. R., Welsh, J. E., Jane, J. A., and Sande, M. A. (1980). Cerebrospinal fluid Outflow Resistance in Rabbits with Experimental Meningitis: Alterations with Penicillin and Methylprednisolone. J. Clin. Invest. 66 (2), 243-253. doi: 10.1172/JCI109850

Sharma, S. K., and Soneja, M. (2011). HIV \& immune reconstitution inflammatory syndrome (IRIS). Indian J. Med. Res. 134 (6), 866-877. doi: 10.4103/09715916.92632

Shelburne, III, S. A., Darcourt, J., White, J. A.C., Greenberg, S. B., Hamill, R. J., Atmar, R. L., et al. (2005). The Role of Immune Reconstitution Inflammatory Syndrome in AIDS-Related Cryptococcus neoformans Disease in the Era of Highly Active Antiretroviral Therapy. Clin. Infect. Dis. 40 (7), 1049-1052. doi: $10.1086 / 428618$

Shin, Y., Lee, S., Shin, J., and Al, E. (2013). VGKC-complex/LGI1-antibody encephalitis: clinical manifestations and response to immunotherapy. J. Neuroimmunol. 265 (1-2), 75-81. doi: 10.1016/j.jneuroim.2013.10.005

Shin, Y. W., Lee, S. T., Park, K.II, Jung, K. H., Jung, K. Y., Lee, S. K., et al. (2018). Treatment strategies for autoimmune encephalitis. Ther. Adv. Neurol. Disord. 11, 1-19. doi: 10.1177/1756285617722347

Singh, N., and Perfect, J. R. (2007). Immune reconstitution syndrome associated with opportunistic mycoses. Lancet Infect. Dis. 7 (6), 395-401. doi: 10.1016/ S1473-3099(07)70085-3

Singh, A. K., Malhotra, H. S., Garg, R. K., Jain, A., Kumar, N., Kohli, N., et al. (2016). Paradoxical reaction in tuberculous meningitis: Presentation, predictors and impact on prognosis. BMC Infect. Dis. 16 (1), 1-11. doi: 10.1186/s12879-016-1625-9

Singhi, P., Jain, V., and Khandelwal, N. (2004). Corticosteroids versus albendazole for treatment of single small enhancing CT lesions in children with NCC. J. Child Neurol. 19, 323-327. doi: 10.1177/088307380401900503

Slom, J. T., Cortese, M. M., Gerber, S. I., Jones, R. C., Holtz, T. H., Lopez, A. S., et al. (2002). An outbreak of eosinophilic meningitis caused by Angiostrongylus cantonensis in travelers returning from the Caribbean. New Engl. J. Med. 346 (9), 668-675. doi: 10.1056/NEJMoa012462

Sonneville, R., Schmidt, M., Messika, J., and Al, E. (2012). Neurologic outcomes and adjunctive steroids in HIV patients with severe cerebral toxoplasmosis. Neurology 79 (17), 1762-1766. doi: 10.1212/WNL.0b013e3182704040

Sonneville, R., Ruimy, R., Benzonana, N., Riffaud, L., Carsin, A., Tadié, J. M., et al. (2017). An update on bacterial brain abscess in immunocompetent patients. Clin. Microbiol. Infect. 23 (9), 614-620. doi: 10.1016/j.cmi.2017.05.004

Steel, H. C., Cockeran, R., Anderson, R., and Feldman, C. (2013). Overview of community-acquired pneumonia and the role of inflammatory mechanisms in the immunopathogenesis of severe pneumococcal disease. Mediators Inflammation 2013, 490346. doi: 10.1155/2013/490346

Sulaiman, T., Salazar, L., and Hasbun, R. (2017). Acute Versus Subacute Community-Acquired Meningitis: Analysis of 611 Patients. Open Forum Infect. Dis. 96 (36), e7984. doi: 10.1093/ofid/ofw172.878

Tauber, M., Khayam-Bakshi, H., and Sande, M. A. (1985). Effects of ampicillin and corticosteroids on brain water content, cerebrospinal fluid pressure, and cerebrospinal fluid lactate levels in experimental pneumococcal meningitis. J. Infect. Dis. Pathog. 151 (3), 528-534. doi: 10.1093/infdis/151.3.528

Teoh, R., O’Mahony, G., and Yeung, V. (1986). Polymorphonuclear pleocytosis in the cerebrospinal fluid during chemotherapy for tuberculous meningitis. J. Neurol. Neurosurg. Psychiatry 233, 237-241. doi: 10.1007/BF00314027

Thwaites, G. E., Bang, N. D., Dung, N. H., Quy, H. T., Oanh, D. T. T., Thoa, N. T. C., et al. (2004). Dexamethasone for the Treatment of Tuberculous Meningitis in Adolescents and Adults. New Engl. J. Med. 351 (17), 1741-1751. doi: 10.1056/ NEJMoa040573

Tunkel, A. R., Hartman, B. J., Kaplan, S. L., Kaufman, B. A., Roos, K. L., Scheld, W. M., et al. (2004). Practice Guidelines for the Management of Bacterial Meningitis. Clin. Infect. Dis. 39 (9), 1267-1284. doi: 10.1086/425368

van de Beek, D., Cabellos, C., Dzupova, O., Esposito, S., Klein, M., Kloek, A. T., et al. (2016a). ESCMID guideline: diagnosis and treatment of acute bacterial meningitis. Clin. Microbiol. Infect. 22, S37-S62. doi: 10.1016/j.cmi.2016.01.007 
van de Beek, D., Brouwer, M., Hasbun, R., Koedel, U., Whitney, C. G., and Wijdicks, E. (2016b). Community-acquired bacterial meningitis. Nat. Rev.: Dis. Primers 2, 1-21. doi: 10.1038/nrdp.2016.74

Venkatesan, A., Tunkel, A. R., Bloch, K. C., Lauring, A. S., Sejvar, J., Bitnun, A., et al. (2013). Case definitions, diagnostic algorithms, and priorities in encephalitis: consensus statement of the international encephalitis consortium. Clin. Infect. Dis. 57 (8), 1114-1128. doi: 10.1093/cid/cit458

Vidal, J. E. (2019). HIV-Related Cerebral Toxoplasmosis Revisited: Current Concepts and Controversies of an Old Disease. J. Int. Assoc. Providers AIDS Care 18, 1-20. doi: 10.1177/2325958219867315

Wang, Q., Wu, Z., Wei, J., and Al, E. (2012). Human Angiostrongylus cantonensis: an update. Eur. J. Clin. Microbiol. Infect. Dis. 31, 389-395. doi: 10.1007/s10096011-1328-5

White, A. C., Coyle, C. M., Rajshekhar, V., Singh, G., Hauser, W. A., Mohanty, A., et al. (2018). Diagnosis and Treatment of Neurocysticercosis: 2017 Clinical Practice Guidelines by the Infectious Diseases Society of America (IDSA) and the American Society of Tropical Medicine and Hygiene (ASTMH). Clin. Infect. Dis. 66 (8), e49-e75. doi: 10.1093/cid/cix1084

Conflict of Interest: $\mathrm{RH}$ has received research support and personal fees from Biofire.

The remaining authors declare that the research was conducted in the absence of any commercial or financial relationships that could be construed as a potential conflict of interest.

Copyright (c) 2020 Gundamraj and Hasbun. This is an open-access article distributed under the terms of the Creative Commons Attribution License (CC BY). The use, distribution or reproduction in other forums is permitted, provided the original author(s) and the copyright owner(s) are credited and that the original publication in this journal is cited, in accordance with accepted academic practice. No use, distribution or reproduction is permitted which does not comply with these terms. 